\title{
Antagonistic behavior between two honeycomb cowfish, Acanthostracion polygonius Poey, 1876, at Curaçao
}

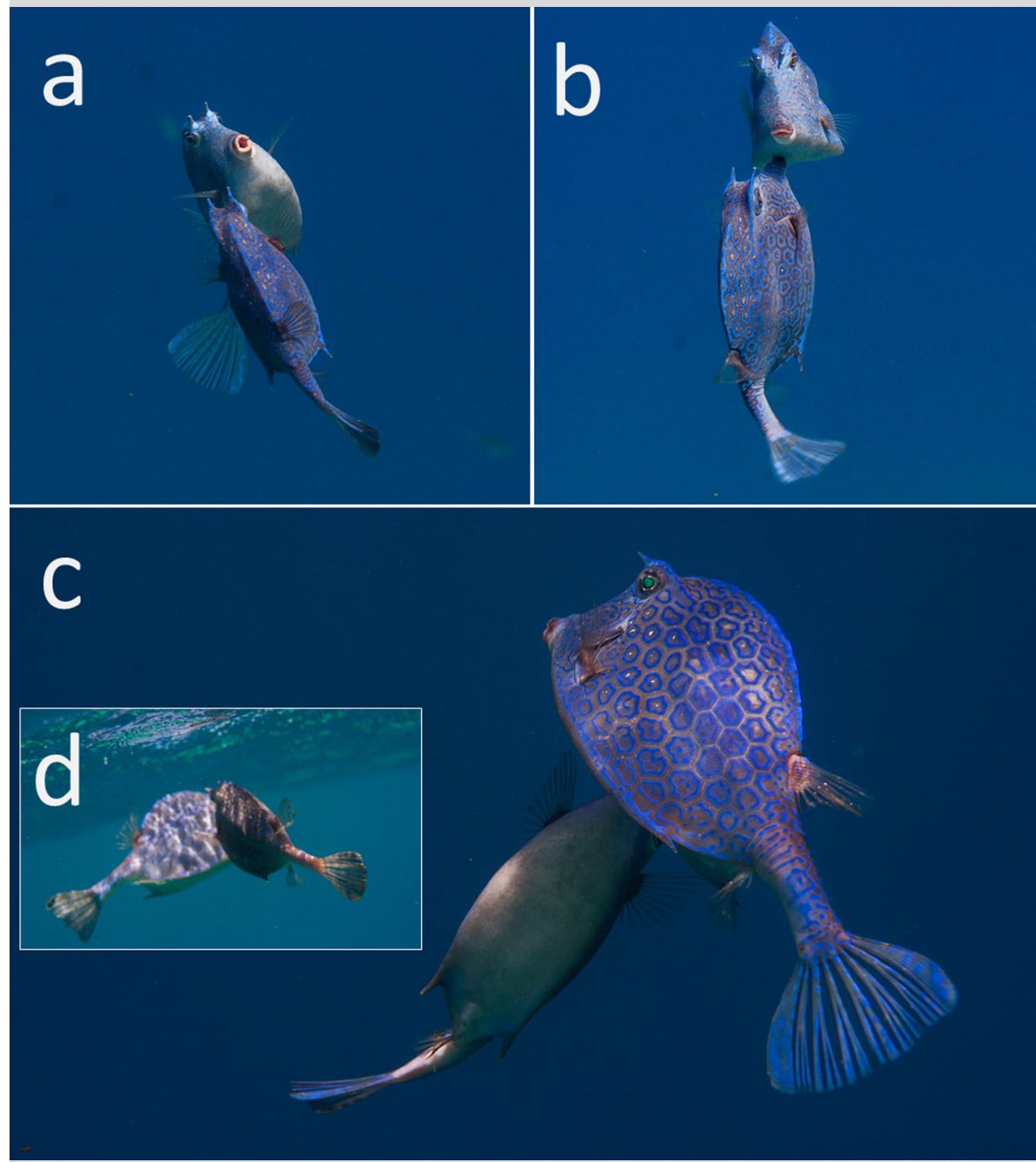

Fig. 1 Acanthostracion polygonius displaying aggressive behavior. a, b Both individuals flaunting their bright blue colors while taking turns biting each other. c, d Smaller fish biting the larger one prior to separating
The honeycomb cowfish, Acanthostracion polygonius Poey, 1876 (Ostraciidae) is easily distinguishable from other Caribbean coral reef fish. Both females and males possess a heavy external bony box with uniformly hexagonal scale plates as armor, as well as a pair of spines projecting from the carapace above the eyes and anterior to the $£$ fin (Moyer 1984). They are known to feed on a variety of invertebrates, including tunicates, alcyonaceans, shrimps, gastropods, and at least 15 species of sponges (Randall 1967; Wulff 1994).

During a coral reef biodiversity survey at Curaçao (June 2017), two A. polygonius individuals were engaged in what appeared to be either a failed mating ritual dance or a male-male territorial dispute

(Fig. 1). It is likely that the encounter is that of a male-male confrontation since the distinctive humming sound of the male prior to gamete release was not heard, nor any spawning was observed (Moyer 1984).

The fighting behavior resembled that of Lactoria diaphana from the Indo-Pacific; upon seeing each other, the pair proceeded to flash and display their bright neon-blue coloration (Moyer 1984). Aggressively charging each other, they took turns sucking/biting their respective underside belly as they rose in the water column (from $6 \mathrm{~m}$ depth) in a circular motion (Fig. 1). Upon reaching the proximity of the surface, with the larger (more dominant) trunkfish attached to the smaller fish, the pair broke off and swam toward the reef in opposite directions. Within the scientific literature, little is known regarding cowfish social structure, reproduction, and territorial competition. This record shines light into a previously known ritual, yet still misunderstood behavior of trunkfishes in the Caribbean.

Acknowledgements JEGH thanks Naturalis Biodiversity Center for research support through a Martin Fellowship CARMABI staff for hospitality, and BW Hoeksema for comments on this manuscript.

\section{Compliance with ethical standards}

Conflict of interest The corresponding author states that there is no conflict of interest.

\section{References}

Moyer JT (1984) Social organization and reproductive behavior of Ostraciid fishes from Japan and the Western Atlantic Ocean. J Ethol 2:85-98 Randall JE (1967) Food habits of reef fishes of the West Indies. Stud Trop Oceanog 5:665-847

Wulff JL (1994) Sponge feeding by Caribbean angelfishes, trunkfishes, and filefishes. In: van Soest RWM, van Kempen TMG, Braekman JC (eds) Sponges in time and space: biology, chemistry, paleontology. AA Balkema, Rotterdam, pp 265-271

J. E. García-Hernández ( $\square)$

Marine Genomic Biodiversity Laboratory, Marine Science Department, University of Puerto Rico-Mayagüez, Isla Magueyes Research Station,

Mayagüez, PR 00667, USA

e-mail: jaaziel.garcia@upr.edu

\section{J. E. García-Hernández}

Naturalis Biodiversity Center, P.O. Box 9517, 2300 RA Leiden, The Netherlands 